\title{
Innovation in Pediatric Medical Devices: Proceedings From The West Coast Consortium for Technology \& Innovation in Pediatrics 2019 Annual Stakeholder Summit
}

Juan Espinoza ${ }^{1,2}$, MD; Kathryne Cooper ${ }^{1}$, MBA; Nadine Afari ${ }^{1,3}$, MS; Payal Shah ${ }^{1,2}$, MS; Sriharinarayana Batchu ${ }^{1}$, BS; Yaniv Bar-Cohen ${ }^{1,4}$, MD

\footnotetext{
${ }^{1}$ The West Coast Consortium for Technology \& Innovation in Pediatrics, Los Angeles, CA, United States

${ }^{2}$ Children's Hospital Los Angeles, Division of General Pediatrics, Los Angeles, CA, United States

${ }^{3}$ Viterbi School of Engineering, University of Southern California, Los Angeles, CA, United States

${ }^{4}$ Children's Hospital Los Angeles, Division of Cardiology, Los Angeles, CA, United States
}

\section{Corresponding Author:}

Juan Espinoza, MD

Children's Hospital Los Angeles

Division of General Pediatrics

4650 Sunset Blvd MS\#76

Los Angeles, CA

United States

Phone: 13233612721

Email: jespinoza@chla.usc.edu

\begin{abstract}
Pediatric medical devices cover a broad array of indications and risk profiles, and have helped to reduce disease burden and improve quality of life for numerous children. However, many of the devices used in pediatrics are not intended for or tested on children. Several barriers have been identified that pose difficulties in bringing pediatric medical devices to the market. These include a small market and small sample size; unique design considerations; regulatory complexities; lack of infrastructure for research, development, and evaluation; and low return on investment. In 2007, the Food and Drug Administration (FDA) created the Pediatric Device Consortia (PDC) Grants Program under the administration of the Office of Orphan Products Development. In 2018, the FDA awarded over US \$30 million to five new PDCs. The West Coast Consortium for Technology \& Innovation in Pediatrics (CTIP) is one of these PDCs and is centered at the Children's Hospital Los Angeles. In February 2019, CTIP convened its primary stakeholders to discuss its priorities and activities for the new grant cycle. In this paper, we have presented a report of the summit proceedings to raise awareness and advocate for patients and pediatric medical device innovators as well as to inform the activities and priorities of other organizations and agencies engaged in pediatric medical device development.
\end{abstract}

(JMIR Biomed Eng 2020;5(1):e17467) doi: 10.2196/17467

\section{KEYWORDS}

medical device development; pediatrics; innovation; proceedings; United States Food and Drug Administration

\section{Introduction}

Pediatric medical devices cover a broad array of indications and risk profiles and have helped to reduce disease burden and improve quality of life for numerous children. However, many of the devices used in pediatrics are not intended for or tested on children. Although some devices such as infant incubators were designed specifically for children, many others are adult devices adapted for pediatric use. Although children and adults can suffer from similar diseases, their device needs are different because of anatomical and physiological differences, physical activity, body structure and functions, and the challenges of growth [1]. Owing to the potential for much longer device use as compared with adults, device longevity and adverse effects of long-term implanted materials can be more significant issues in children. According to a national survey of government-associated clinicians conducted by the Food and Drug Administration (FDA) and the National Center for Advancing Translational Sciences, despite cutting-edge research and improved technologies to advance pediatric device development, the percentage of novel pediatric devices designed, evaluated, and approved for pediatrics is only about a quarter 
of those approved for adults [2]. In the same survey, 91\% of clinicians reported that a new or improved device is needed, and $64 \%$ were dissatisfied with existing devices [3].

Several factors have been identified that pose difficulties in bringing pediatric medical devices to the market. These include a small market and small sample size; unique design considerations; regulatory complexities; lack of infrastructure for research, development, and evaluation; and low return on investment [4]. The end result of these barriers is that very few new devices end up receiving specific pediatric regulatory approval from the FDA. In 2017, 66 new devices were approved through the premarket approval and humanitarian device extension pathways; only 18 of those were indicated for use in the pediatric population and even fewer for children younger than 18 years [2]. Of the remaining 48 devices approved for adults, $88 \%(n=42)$ were determined by pediatric experts to have potential applicability in pediatric diseases [2]. Due to the paucity of approved devices, children are potentially exposed to greater risk because providers are forced to use either off-label devices or less-effective therapies.

The FDA has committed to advancing policies to encourage the development of safe and effective medical devices designed specifically for pediatric patients. In 2007, with the enactment of Section 305 of the Pediatric Medical Device Safety and Improvement Act, the Pediatric Device Consortia (PDC) Grants Program was created and administered by the FDA's Office of Orphan Products Development [5,6]. The primary aim of this program is to facilitate the development, production, and distribution of medical devices. PDC serves providers with scientific and regulatory advice, physical and design resources, identifying funding sources and business assistance for the development of medical devices. The consortia have assisted the development of more than 1000 proposed medical devices in various stages of the total product life cycle. There are 19 unique pediatric medical devices available to patients as a result of this program, including a needle-free blood collection device, a surgical vessel sealing system, and a rapid vascular infusion device [7]. The PDC program has awarded US \$37 million to various consortia since 2009 for pediatric device research and development (Figure 1) [6,7]. The FDA is also collaborating with industry stakeholders to build the National Evaluation System for health Technology [8] to generate better evidence for medical device evaluation and regulatory decision making, and incorporating real-world evidence generation strategies for more efficient and balanced approaches toward pre- and postmarket data collection [7,9].

Figure 1. Past and current Pediatric Device Consortia 2009-2018.

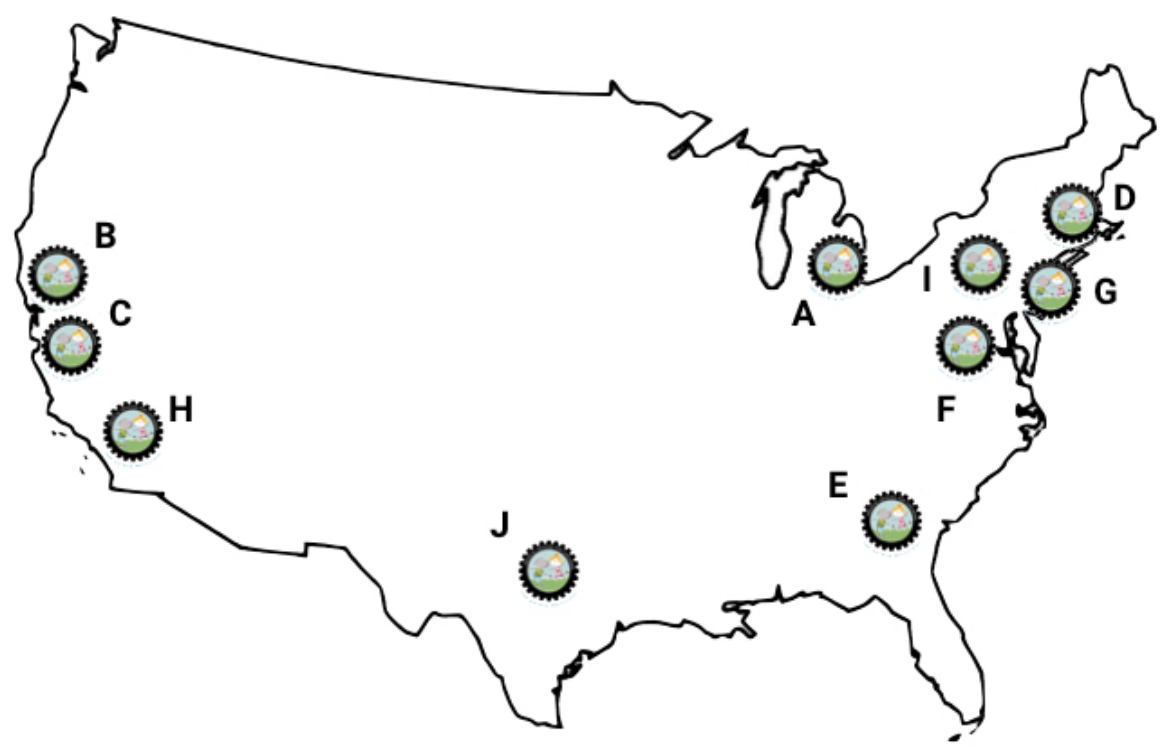

2009

The Michigan Pediatric Device
Consortium (A)
University of California, San Francisco
Pediatric Device Consortium (B)
The MISTRAL Device Consortium (C)
The Pediatric Cardiovascular Device
Consortium (D)
Consortium (D)
2011

2013

$$
\begin{array}{cc}
\begin{array}{c}
\text { University of Michigan MPED \& PMDI } \\
\text { Pediatric Medical Device Consortium (A) } \\
\text { University of California, San Francisco } \\
\text { Pediatric Device Consortium (B) }
\end{array} & \begin{array}{c}
\text { University of Michigan Pediatric Device } \\
\text { Consortium (A) }
\end{array} \\
\begin{array}{c}
\text { Atlanta Pediatric Device Consortium (E) } \\
\text { Boston Pediatric Device Consortium (D) }
\end{array} & \begin{array}{c}
\text { Atlantic Pediatric Device Consortium (E) } \\
\text { National Capital Consortium for Pediatric } \\
\text { Device Innovation (F) }
\end{array} \\
& \begin{array}{c}
\text { New England Pediatric Device Consortium } \\
(\mathbf{G})
\end{array} \\
& \begin{array}{c}
\text { Southern California Center for Technology } \\
\text { and Innovation in Pediatrics (H) }
\end{array} \\
\text { Philadelphia Regional Pediatric Medical } \\
\text { Device Consortium (I) }
\end{array}
$$

A

2018

UCSF-Stanford Pediatric Device

Consortium $(\mathrm{B}+\mathrm{C})$

National Capital Consortium for Pediatric Device Innovation 2.0 (F)

The West Coast Consortium for Technology

\& Innovation in Pediatrics (H)

Pennsylvania Pediatric Medical Device Consortium (I)

Southwest National Pediatric Device Innovation Consortium (J) 


\section{About The West Coast Consortium for Technology \& Innovation in Pediatrics}

The West Coast Consortium for Technology \& Innovation in Pediatrics (CTIP) is a PDC centered at the Children's Hospital Los Angeles (CHLA) and the University of Southern California (USC). Established in 2011 and first funded by the US FDA in 2013, CTIP promotes the commercialization and clinical use of pediatric medical device technology. In August 2018, CTIP was awarded a new US \$6.6 million P50 grant from the FDA to continue its efforts to advance the research and development of medical devices for children.

CTIP attempts to address an important component often missing from pediatric device innovation, that is, simultaneously engaging clinicians, engineers, regulators, hospital administrators, patients, and the business community in the process of assessment and development of technology. For portfolio companies, CTIP fosters networking opportunities, direct and indirect financial support, and guidance on issues related to, but not limited to, intellectual property (IP), prototyping, engineering, testing, grant writing, and clinical trial design. CTIP has a network of children's hospitals, academic institutions, accelerators, and incubators across The West Coast to support the commercialization of pediatric medical devices. CTIP network members include the University of California, Los Angeles; Oregon Health \& Science University; University of Southern California; University of California, San Diego; University of California, Berkeley; Seattle Children's Hospital; Cedars-Sinai Accelerator; The Lundquist Institute (formerly La BioMed); and Project Zygote (Figure 2).

Figure 2. List of The West Coast Consortium for Technology \& Innovation in Pediatrics (CTIP) member institutions.

\begin{tabular}{cll}
\hline No. & \multicolumn{1}{c}{ Institution } & \multicolumn{1}{c}{ Role } \\
\hline 1 & Children's Hospital Los Angeles & Principal Site \\
2 & Oregon Health \& Science University & Funded Academic Partner \\
3 & University of California Los Angeles & Funded Academic Partner \\
4 & University of California San Diego & $\begin{array}{l}\text { Unfunded Partners and } \\
\text { Collaborators }\end{array}$ \\
5 & University of Southern California & $\begin{array}{l}\text { Unfunded Partners and } \\
\text { Collaborators }\end{array}$ \\
6 & Seattle Children's Hospital & $\begin{array}{l}\text { Unfunded Partners and } \\
\text { Collaborators }\end{array}$ \\
7 & University of California Berkeley & $\begin{array}{l}\text { Unfunded Partners and } \\
\text { Collaborators }\end{array}$ \\
& & Unfunded Partners and \\
8 & Cedars-Sinai Accelerator & Collaborators \\
& & Unfunded Partners and \\
9 & The Lundquist Institute & Collaborators \\
10 & Project Zygote & $\begin{array}{l}\text { Unfunded Partners and } \\
\text { Collaborators }\end{array}$ \\
\hline
\end{tabular}

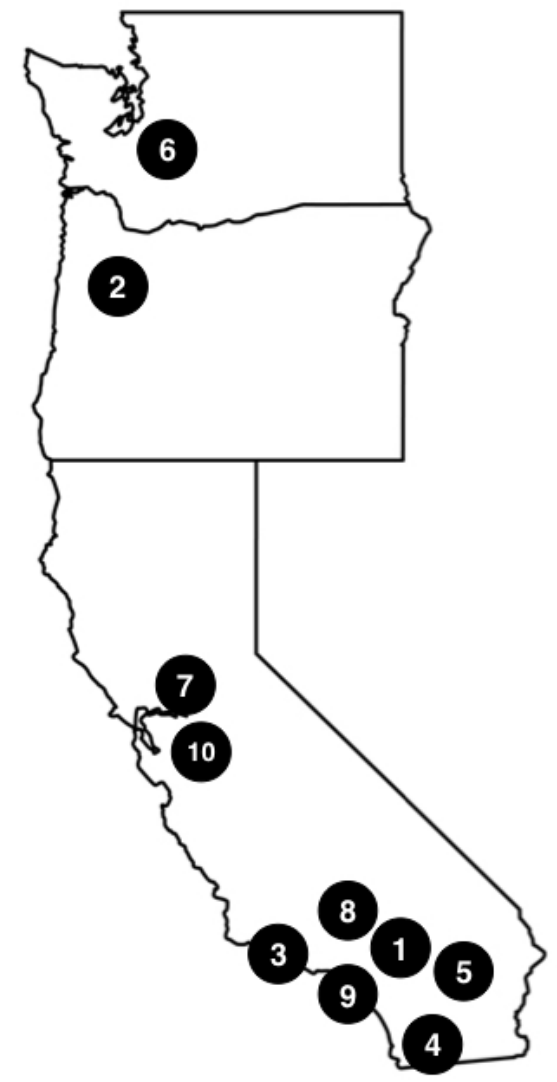

CTIP aims to do the following:

- Build upon our national network of multidisciplinary stakeholders to identify and foster promising pediatric medical device projects.

- Increase awareness around the need for novel pediatric medical device development.

- Overcome current barriers to commercialization with a particular focus on establishing academia's role in alleviating these barriers.

- Develop and implement strategies that will sustain a productive needs-driven pipeline of new pediatric medical devices.

\section{The 2019 West Coast Consortium for Technology \& Innovation in Pediatrics Summit}

On February 1, 2019, the CTIP hosted a consortium summit at CHLA to discuss pediatric medical devices, regulatory challenges, reimbursement strategies, and prototype, design, and business development. The CTIP's advisory board and steering committee members shared current industry knowledge and research in the field of Medtech and explored different pathways to commercialization success. During the discussion sessions, participants were encouraged to focus on ways to enhance collaboration between their institutions and CTIP. The information summarized herein reflects the knowledge and opinions of the 2019 summit participants (Table 1). 
Table 1. List of 2019 summit attendees.

\begin{tabular}{|c|c|c|c|}
\hline Name & Title & Organization & $\begin{array}{l}\text { The West Coast Consortium for Technol- } \\
\text { ogy \& Innovation in Pediatrics affiliation }\end{array}$ \\
\hline Katz, Samantha & $\begin{array}{l}\text { Venture General Manager and Health Direc- } \\
\text { tor }\end{array}$ & BCG Digital Ventures & Advisory board \\
\hline Rousset, Jessica & Chief Operating Officer & Cure Pharmaceuticals & Advisory board \\
\hline Edgerton, Kathryn & Partner & Nelson Hardiman Healthcare Lawyers & Advisory board \\
\hline Cramer, Charlotte & Innovation Strategist, Innovation Studio & CHLA $^{\mathrm{a}}$ & CHLA staff \\
\hline Crown, Kelly & Innovation Strategist, Innovation Studio & CHLA & CHLA staff \\
\hline Eric, Meyer & Innovation Strategist, Innovation Studio & CHLA & CHLA staff \\
\hline Kulkarni, Omkar & Chief Innovation Officer & CHLA & CHLA staff \\
\hline Martine, Broome & $\begin{array}{l}\text { Portfolio and Alliance Manager, Office of } \\
\text { Technology Commercialization }\end{array}$ & CHLA & CHLA staff \\
\hline $\mathrm{Ng}$, Victoria & Innovation Consultant, Innovation Studio & CHLA & CHLA staff \\
\hline Afari, Nadine & Program Manager & $\mathrm{CTIP}^{\mathrm{b}}, \mathrm{CHLA}$ & CTIP staff \\
\hline Bar-Cohen, Yaniv & Co-Director & CTIP, CHLA & CTIP staff \\
\hline $\begin{array}{l}\text { Batchu, Srihari- } \\
\text { narayana }\end{array}$ & Program Administrator & CTIP, CHLA & CTIP staff \\
\hline Cooper, Kathryne & Co-Director & CTIP, CHLA & CTIP staff \\
\hline Espinoza, Juan & Director & CTIP, CHLA & CTIP staff \\
\hline Shah, Payal & Research Associate & CTIP, CHLA & CTIP staff \\
\hline Senn, Sean & Managing Partner & Accelerator AIX & Entrepreneur in residence \\
\hline Bernstein, Christina & President & BB Medical Surgical, Inc & Entrepreneur in residence \\
\hline Furth, Neelima & Regulatory Consultant & Best Laid Plans, Inc & Entrepreneur in residence \\
\hline Patnaik, Meeta & $\begin{array}{l}\text { SVP Clinical Development and Medical } \\
\text { Affairs }\end{array}$ & Bionaut Labs & Entrepreneur in residence \\
\hline Rushi, Amit & $\begin{array}{l}\text { Vice President, Product, Marketing, and } \\
\text { Business Development }\end{array}$ & GraftWorx & Entrepreneur in residence \\
\hline Hager, Earle & Managing Partner & The Neutrino Donut, LLC & Entrepreneur in residence \\
\hline Ulmer, Kwame & Principal & Ulmer Ventures, LLC & Entrepreneur in residence \\
\hline Plush, Robert & VP of Pediatrics & Surgical Theater & Entrepreneur in residence \\
\hline Sheridan, David & $\begin{array}{l}\text { Codirector, Emergency Medicine Clinical } \\
\text { Innovation Program }\end{array}$ & Oregon Health \& Science University & Steering committee \\
\hline Watson, Andrew & Senior Director of Technology Transfer & Oregon Health \& Science University & Steering committee \\
\hline $\begin{array}{l}\text { Sue Swanson, } \\
\text { Wendy }\end{array}$ & Chief of Digital Innovation & Seattle Children's Hospital & Steering committee \\
\hline Horse-Grant, Desert & Senior Director of Research and Innovation & University of California Los Angeles & Steering committee \\
\hline Levi, Dan & Interventional Pediatric Cardiologist & University of California Los Angeles & Steering committee \\
\hline Flores, Ruben & $\begin{array}{l}\text { Director, Office of Innovation and Commer- } \\
\text { cialization }\end{array}$ & University of California San Diego & Steering committee \\
\hline Blanco, Cesar & $\begin{array}{l}\text { Senior Director of Research and Develop- } \\
\text { ment Programs, Regulatory and Quality }\end{array}$ & $\begin{array}{l}\text { USC Alfred E. Mann Institute for } \\
\text { Biomedical Engineering }\end{array}$ & Steering committee \\
\hline Grossman, Elissa & $\begin{array}{l}\text { Associate Professor of Clinical Entrepreneur- } \\
\text { ship }\end{array}$ & USC Marshall School of Business & Steering committee \\
\hline Richmond, Frances & $\begin{array}{l}\text { Chair, Department of Regulatory and } \\
\text { Quality Sciences }\end{array}$ & USC School of Pharmacy & Steering committee \\
\hline Khoo, Michael CK & $\begin{array}{l}\text { Professor of Biomedical Engineering and } \\
\text { Pediatrics }\end{array}$ & USC Viterbi School of Engineering & Steering committee \\
\hline
\end{tabular}




\begin{tabular}{|c|c|c|c|}
\hline Name & Title & Organization & $\begin{array}{l}\text { The West Coast Consortium for Technol- } \\
\text { ogy \& Innovation in Pediatrics affiliation }\end{array}$ \\
\hline Loeb, Gerald & $\begin{array}{l}\text { Professor of Biomedical Engineering and } \\
\text { Neurology }\end{array}$ & USC Viterbi School of Engineering & Steering committee \\
\hline $\begin{array}{l}\text { Tolomiczenko, } \\
\text { George }\end{array}$ & $\begin{array}{l}\text { Admininistrative Director, Health, Technol- } \\
\text { ogy, and Engineering Program }\end{array}$ & USC Viterbi School of Engineering & Steering committee \\
\hline
\end{tabular}

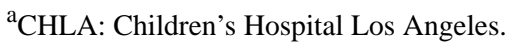

${ }^{\mathrm{b}}$ CTIP: The West Coast Consortium for Technology \& Innovation in Pediatrics.

\section{Summit Proceedings}

\section{Session 1: Pediatric Medical Devices-Where Should Consortium for Technology \& Innovation in Pediatrics Focus Resources and Efforts?}

Session 1 was led by Dr. Juan Espinoza and Dr. Yaniv Bar-Cohen, the principal investigator (PI) and co-PI of CTIP, respectively. They began by leading a discussion about the importance of defining "success" for CTIP. For the FDA, "success" refers to device approvals and commercialization. These are important milestones that validate the need for programs such as the Pediatric Device Consortia. However, these are rare events on longer timelines; therefore, the focus should be on process measures that show progress toward those key milestones.

One of CTIP's goals is to increase awareness in the Medtech community around the unique issues faced by pediatric medical devices, pediatric indications, and labeling. Although the legal and regulatory framework used by the FDA for devices is complex, the economic and market barriers to medical and surgical device development for children are significant. In the future, as early as 2020, CTIP could explore current medical devices on the market that could potentially pursue pediatric classification. CTIP's leadership team discussed that the portfolio should have a range of Class 2 and Class 3 devices. Whether CTIP should focus in certain areas, such as orthopedics or implantable devices, was also discussed, with the consensus being that CTIP should continue to support projects that address unmet needs regardless of the focus area.

The majority of medical device companies continue to shy away from developing pediatric medical devices because the process is costly and complicated. Many believe that the market is small with limited opportunities for return on investment (ROI). However, it was pointed out that the United States is the largest market for pediatric medical devices whose growth is attributed to an increase in the incidence of chronic diseases such as heart disease, diabetes, and obesity, increasing awareness about adolescent health and behavioral health and increasing the demand for medical devices in pediatric hospitals and clinics. Pediatric Medtech remains to be a dynamic sector, with new technologies and products emerging every year. Many investors often overlook investment opportunities within pediatric medical devices; CTIP firmly believes that the pediatric Medtech sector can generate excellent investment opportunities.

CTIP understands that one of the best ways to assess whether a given company is focused on innovation and success is to look at the company's product pipeline, team structure, and research and development (R\&D) efforts. Innovation in medicine is primarily driven by both need and the size of a market, and the demand for pediatric devices does not always cover the necessary $R \& D$ investment required to bring these devices to the market. Investors will also look for these trends and patterns. Entrepreneurs in this space need to maintain an unconventional way of thinking when presenting their devices to investors and appeal to a variety of motivations, including long-term ROI, social impact, and launching additional, often adult-targeted, products. Investors should also be educated on evaluating pediatric Medtech differently, taking into consideration many of the previously mentioned factors.

There are several key points in a Medtech company's life cycle, and each stage has certain ramifications for an investor. Startups often face years of losses and cash outflows, as the management tries to lead new products through clinical and device trials, regulatory processes, and eventually into the market. CTIP and our consultants working with the portfolio members understand that very few Medtech companies mature into large, independent players. For many companies, the goal is licensing or acquisition of their technology or IP. Despite the unique considerations for pediatrics, the total product life cycle of pediatric medical devices will be familiar to Medtech investors; companies should leverage that familiarity in their investor pitches.

CTIP's leadership team shared with the group that as pediatrics devices are a unique subset of the medical device industry, PDC program activities need to cater to that market. Before a medical device can be marketed in the United States, the FDA has to evaluate and approve the device. Although not all product approvals require expensive device trials, many products that drive revenue growth for the pediatric sector require data on efficacy and safety before the FDA permits their sale. It is also worth noting that approval is not the end of the regulatory process; the FDA requires ongoing monitoring and reporting and can order devices off the market if hidden dangers reveal themselves in subsequent years.

Risk analysis is an essential component of a quality management system. CTIP should focus on derisking devices early on. CTIP consultants work closely with the startup's risk management team to create a plan for applying risk management procedures to the design and manufacture of their pediatric medical device. It is crucial to document how risks are identified, evaluated, and traced. The pediatric device innovator's plan should define the entire scope of the risk management process, including the purpose of the device, its life cycle, responsible parties and authorities, and data collection and analysis all the way through postproduction. 
Emphasis was put on CTIP's initial evaluation of the company and asking clear go/no-go questions for every company: "How good or bad is this idea? What are the risks? What will the market bear? How will payers receive this?"

Other key questions that companies should be able to answer include:

1. How many units do you think you can sell?

2. What price could you get?

3. Walk us through how is this going to work?

4. How is your business sustainable?

This is meant to push companies to think through their business and sustainability plans.

Suggestions from the participants included the following:

1. CTIP should create risk-analysis worksheets for companies to complete during the initial evaluation.

2. During the evaluation call, CTIP should ask companies to share the top three markets for their device and consider how they might pursue market expansion. During the evaluation call, companies should also be asked, "What your sustainability plan is for the long term?" "What the other commercialization possibilities are?"

3. CTIP should keep in mind that a mature technology company is valued partly by traditional methods, including profit, revenue growth, and overall sales. Derisking these elements, particularly in the early stages, can add significant value. Of course, because technology is an ever-changing space, even what we consider a successful Medtech company can rise or fall based on an unproven product or even an announcement of a new development.

One of the other considerations that CTIP and companies need to be aware of is the issue of reimbursement. The reimbursement strategy is just as important as the regulatory strategy. Reimbursement assessment is used largely to help make informed decisions about the coverage of health care services by private and public payers. Reimbursement influences product development strategy from an early stage and drives decision making about potential asset acquisitions. It also combines health economics, outcomes research, pricing and reimbursement, external affairs, key opinion leader engagement, advocacy, and government lobbying. The suggestion was that CTIP should provide portfolio members with key reimbursement information to ensure startup success.

Some of the key reimbursement questions CTIP should address with portfolio members are as follows:

1. What are the priorities in the hospital?

2. How do pediatric hospitals assess value and who is involved?

3. How do hospital decision makers decide what they want?

4. What are the barriers for adoption?

5. What does the reimbursement approval process look like?

6. What are the relevant Centers for Medicare \& Medicaid Services and insurance policies involved?

The discussion also focused on creating an innovation roadmap to connect entrepreneurs with the decision makers in the hospitals and/or create a roadmap for important decisions. This innovation roadmap should consider both the hospital business development process and entrepreneurs. This roadmap would remind innovators of whom they need to connect with during this journey. Having regular opportunities to network and build relationships between stakeholders is important to more effectively work together. Clear communication that centers on sharing resources, information, and best practices among stakeholders can also help to achieve shared goals.

As a part of CTIP Activities for year 1, the group recommended developing a business relationship with the Los Angeles Mayor's office with the possibility of a pipeline between the Mayor's Office, the Los Angeles Bioscience Investment Fund, CHLA, and others to create more awareness about opportunities in pediatric Medtech. In 2015, the Los Angeles County Board of Supervisors made economic development a priority to stimulate regional job growth and lift residents out of poverty. Seven industries were targeted based on their proven ability to create jobs and wealth. Bioscience was the first of the industry sectors selected by Los Angeles county for focused support. The Los Angeles region generates cutting-edge bioscience R\&D and a trained workforce capable of launching and supporting enterprises emerging from local research institutions and incubators. Over past economic cycles, including the Great Recession, bioscience jobs have proven unaffected by economic downturn. Increased awareness in the business and investor community would facilitate follow-on investments in CTIP portfolio members.

Nearing the end of the first session, the participants highlighted the need to understand that in most hospitals, if the projects do not benefit the home institution, then there is limited incentive to move forward. Seattle's Children's Hospital encourages a dual incentive for both the hospital and the entrepreneur, which also encourages quality control and safety. One suggestion was brought up to host office hours at CHLA and document what has been done/shared between entrepreneurs and hospitals. This could reduce communication barriers between entrepreneurs, clinicians, and administrators. CTIP could incentivize this process by funding participants' time as consultants. This could be a bridge building activity that makes the process more official. The CTIP's leadership will explore connecting with human resources on challenges or issues regarding this suggestion.

The first session ended energetically with other programing solutions as follows:

1. Collecting success stories and sharing the pathways/stories from both the entrepreneur side and the hospital side.

2. Sharing stories in a video format or blog featured on the CTIP site could be beneficial to Medtech commercialization.

\section{Session 2: Business Models for Pediatric Medical Devices-How Do We Advise Companies on Their Path Toward Commercialization?}

Session 2 was led by Elissa Grossman, MBA, PhD-CTIP steering committee member; Kathryne Cooper, MBA, CTIP Co-Director; and Christopher Del Vecchio, MS, JD-CTIP, steering committee member. The session began with a discussion 
of the current CTIP portfolio. Many CTIP companies (roughly 50) are at an early stage. The pediatric market as a subdivision of health care accounts for approximately $25 \%$ of the US population (individuals younger than 21 years). This smaller market results in many businesses having limited resources and needing to pursue nontraditional funding opportunities. CTIP should consider the nuances of the matchmaking process and match investor money with the right entrepreneur. It is important to ensure that interests are aligned, connect with investors to strategize where they can invest their money, and work with business development consultants to create different kinds of business models and commercialization strategies.

Historically, the requirements of the American market have set standards for the design and development of products, functions, and processes. Although the United States will continue to be the most important market for the next decade, global markets will become increasingly relevant for pediatric Medtech startups. These markets will provide opportunities for new customers and expand operational activities, such as manufacturing, shared services, and R\&D.

For therapeutics and diagnostics markets where Medtech holds significant new potential, R\&D and business development investments should lead to the creation of new technologies that have both clinical efficacy and cost-effectiveness. This will require companies to leverage existing global commercial, development, and operating capabilities. Companies may consider partnerships with other organizations that have existing capabilities. However, all partnerships should clearly delineate any IP considerations. When an innovator engages with a contractor or consultant, and the innovator expects to own the IP arising from the engagement, the innovator should expressly provide clarification for this in the engagement agreement. Lack of clarity around the important issues such as who owns the company assets, documents, and IP can pose a significant risk.

Given the rapidly evolving nature of Medtech, it is important for entrepreneurs to reflect on how successful teams choose which ideas to pursue. Their business model should include a clearly articulated plan for how they make these decisions. These decisions are informed by a clear understanding of health care technology purchasing and the relevant processes and people involved in those decisions. The Medtech industry as a whole faces challenges to the legacy business models and strategic choices that companies have used to excel in the past.

Success in Medtech requires a clear and consistent focus on delivering differentiated value and performance to customers, shareholders, and users. A new "value bar" forces Medtech startups to rethink how they can effectively create a product portfolio that will meet this ever-increasing set of expectations. It is no longer sufficient to demonstrate the marginal product benefits for new product launches. A more diverse set of stakeholders are now involved in the adoption and decision-making process for Medtech products. A broader set of stakeholders to support product adoption is needed.

Suggestions from the participants included the following:

1. CTIP companies should try to work with hospitals to evaluate outcome measures and costs.
2. Business models that CTIP companies should consider include value-based models that focus on cost containment and help the hospital be more profitable.

3. One needs to be careful about the technology sector, which can be boom or bust. The same is true for individual companies and market segments within the Medtech space.

4. It will be helpful to read the 2013 book by Michael Raynor and Mumtaz Ahmed (The Three Rules: How Exceptional Companies Think) [10], which brings discipline to the field by identifying rigorous, research-backed principles that guide exceptional companies in two ways: (1) better before cheaper: rather than competing solely on price, companies achieve sustainable success by focusing on delivering differentiated value; and (2) revenue before cost: the advantages of higher revenue are more valuable and durable than the advantages of lower cost.

Medtech companies could have a significant customer base and still not show consistent profits. In many cases, they lose money, sometimes a significant amount, as these companies build out capacity and develop a market for their products. To build differentiated products, many companies need to consider transformational innovation: innovation that creates and delivers customer value through novel products, solutions, and business models that address these unmet market needs.

To improve their business model, companies should ask themselves these key questions:

1. How will your customers hear about your medical device?

2. What is the value proposition of your device?

3. Who do entrepreneurs need to speak with to educate the customer?

CTIP can assist in finding a systematic approach to facilitate entrepreneurs' connection with those making purchasing decisions. Entrepreneurs need to understand who the decision makers are for their potential customers. CTIP is exploring creating a repeatable operational process around this topic and understanding how it can incentivize decision makers to attend, present, and engage. Encouraging innovation and using analytics to share success metrics are proactive ways to connect with hospital administrators. With the help of CTIP, companies can complete a derisk tech worksheet to decide if they want to design for manufacturing, acquisition, or licensing.

There are a couple of key points to consider when hospitals partner with an entrepreneur:

1. How is the collaboration structured and defined?

2. How are entrepreneurs evaluating their technology? Solely based on profit?

Hospitals evaluate new technology based on value and cost savings. Companies and CTIP can work with hospitals to collectively define success and quantify the positive clinical impact of devices.

For existing companies with adult devices, there are opportunities to expand into pediatrics. Options include developing the product themselves or licensing their IP to a second company to develop the pediatric version. This could be a novel approach to bring more pediatric medical devices to 
the market. CTIP can match companies with Entrepreneurs-In-Residence who can help portfolio members explore and negotiate these types of arrangements.

The group also discussed other nonprofit-driven business models such as B-Corps and 501(c)3 nonprofits. CTIP can help companies find a way to blend the nonprofit model with how to operate as a business that supports the device. Companies that form a nonprofit organization do not have to make decisions based on a profit motive; rather, they can operate on mission instead. If the values of new investors are not aligned, companies do not have to take their offers, giving entrepreneurs more latitude. A major consideration is that entrepreneurs need to demonstrate how their product development and mission meet the legal requirements for being structured under these mechanisms.

The discussion then moved to small business innovation research and small business technology transfer (SBIR/STTR) program issues:

1. Some institutes have started evaluating SBIR/STTR proposals using a similar rubric to National Institutes of Health research grants such as R01. Most small companies do not typically have the skills or background to write these grants. CTIP can assist companies by connecting them to grant writing support.

2. The question raised was if CTIP could assemble a team of PhDs and other experts to help with grant writing.

3. It would be very helpful if CTIP can host workshops for portfolio companies at different stages of development but focus on similar class devices and projects. These workshops can teach reimbursement pathways, SBIR grant basics and different business model strategies, perhaps as a 4-week course.

4. CTIP should curate case studies from its portfolio that exemplify key processes and decisions and share them with the rest of the portfolio to learn from.

\section{Session 3: Food for Thought-Derisking Strategies for the Commercialization of Medical Devices}

Session 3 was led by Cesar E. Blanco, PhD - CTIP Steering Committee, on derisking strategies for the commercialization of medical devices. The "valley of death" [11] in startup formation is often difficult to traverse for pediatric medical device companies in particular. This is because investors are reluctant to support startups if their products have not yet been derisked. In addition, the pediatric device market is seen by some as niche and considered risky from the beginning. CTIP can assist with derisking in two main ways: (1) by providing funding for prototype and design so entrepreneurs can take their first iteration product to their stakeholders for feedback and (2) by pairing the entrepreneur with an Entrepreneur-in-Residence or a consultant via CTIP's Consultant-Company Match Program. CTIP can serve as a device derisking incubator, with the aim of helping entrepreneurs with business planning, regulatory support, clinical trials, prototyping, and preclinical work.

Medtech startups transform and change in many ways over time and entrepreneurs should know that as they develop a Medtech device. The team and individuals involved in the process change as the company needs change. This will impact how the company matures. In the ideation phase, a company will seek technical expertise, creativity, and team members who can push the boundaries in terms of development and innovation. In the next stage of the R\&D process, companies consider and filter design input/requirements. This is where innovators start focusing on meeting design requirements; the need for out of the box thinkers may be less. The team is likely to change again as R\&D expands, and their funding increases. Companies should be as intentional about the people on their team as they are about the product. Teams and companies can create a list of competencies, skills, and values. As companies continue to grow and transform, founders and teams should continually re-evaluate their product, their market, and their team composition.

The cost of medical technology is not declining, and many medical professionals equate progress in medicine to the increasing use of sophisticated technology that is often expensive. There is an urgent need to address high-cost small markets through the development and use of appropriate technology in accordance with the needs and priorities of pediatric patients. A number of simple and inexpensive quality measures that have the potential to improve outcomes substantially without the need for expensive equipment should be instituted before embracing high-end technology. Innovations to reduce health care costs are another key component of commercialization success. Medtech entrepreneurs need to learn how to decide how much to charge the product, which requires more thought than simply calculating costs and adding a markup. Entrepreneurs, hospital administrators, and clinicians need to assess and consider how much they value the product or service they buy. Figuring out how much the customer (hospital or patient) values the product or service and pricing is paramount to success. Another important consideration for pricing is whether a product should have multiple price points based on features, use case, or customer.

There was also a discussion about reviewing prototyping, which can be funded by CTIP and is an essential part of medical device development and manufacturing. Not only is it critical for refining the design of a product and testing safety and performance, prototyping is a must for startups, so that they can demonstrate how the product looks and functions. Without prototypes, it would be nearly impossible to secure funding for production. Some nimble startups use rapid prototyping and low-volume manufacturing to compete with established companies and gain market share to save time and money.

Prototypes also play a critical role in obtaining quality feedback from end users, clinicians, and hospital administrators; having a high-fidelity prototype can lead to better design optimization within accelerated development windows. Prototyping is about speed and fast turnaround time. The goal is to find flaws, imperfections, and other opportunities for improvement and then address them quickly. As design specifications advance, the device may be able to enter more than one market. Design should be simplified, and entrepreneurs and engineers may need to let go of the bells and whistles. This can be a critical issue for software and digital health and can lead to issues they did not foresee. Clinicians with solutions often have too many 
features and need to refine their designs. Finally, innovators need to be aware of different types of prototypes, such as prototypes for clinical studies, as opposed to prototypes for the evaluation of commercial product fit.

When thinking about derisking their commercialization strategy, entrepreneurs should consider the following questions:

1. What is your market and how big is it?

2. How will you capture and protect IP?

3. When and how can you add value?

4. When is this exciting to another strategic partner?

5. Can this be leveraged in some other market or application?

While discussing team dynamics with innovators, it is important to focus on identifying if the team that founded the company wants to be in full control; how much control is willing to let go of? It is important to know this upfront; as the company matures and acquires investors, they will have to release some control. Companies need to understand their market and development costs. CTIP can host a workshop to help companies identify opportunities to expand, fully explore their value proposition, and make sure they define their customers correctly (the end user is often not the customer in health care). Understanding the dynamic changes and shareholders who both create and hinder change is critical to Medtech success. Marketing leaders push for quicker cycle times, engineering leaders want cutting-edge technology, supply chain leaders seek low-cost initiatives, clinicians want to provide quality care, investors want an ROI, and hospitals want to maintain high quality and low costs. Companies need to be able to deliver a compelling proposition to each of these stakeholders.

With respect to the regulatory process, there are two important parts to a medical device: (1) the device itself and (2) the documentation that supports the design and indication for use, including preclinical studies, efficacy studies, quality management systems, patents, etc. There is a significant value in how well this documentation is organized and updated. It is important for entrepreneurs to develop these assets early. CTIP will need to remind portfolio members about the need to appropriately document quality control and reproducibility. Documentation is critical in the early stages; in some ways, the paperwork becomes more important than the device itself, early on.

Finally, the group addressed the timing of investor outreach. In general, this should be in line with device and company maturity. An example discussed was a device startup company that ran into difficulties with a thermally triggered adhesive. This device uses an adhesive to secure and hold in place pads that connect to a string device that helps close sutures. It was intended to minimize scarring and promote faster healing. The device did this by reducing the strain across incisions, thereby decreasing the size of scars. Currently, this device is challenged by temperature and adhesive strength. Current testing could not meet the high adhesive strength requirements. This company is working on a new formula but has limited funding for this phase of R\&D. In this scenario, although the suture closure device is very mature, they still have not solved significant product issues and are having trouble attracting investors. In such cases, CTIP can help companies identify exits, strategize multiple exit points, and articulate concepts to investors.

\section{Session 4: The Business of Pediatric Medical Devices-Reimbursement Strategy and Food and Drug Association Regulation}

Session 4 was led by Frances Richmond, PhD - CTIP Steering Committee, in which she discussed the role of reimbursement and regulatory strategies. The innovation "valley of death" (Figure 3) [11] prevents the progress of science from the laboratory bench to the point where it provides the basis of a commercially successful business or product in a couple key ways. Medtech startups often need help to access knowledge, capacity, resources, and people outside of their company. Organizations such as CTIP could develop innovation processes and infrastructure to reduce risk and uncertainty for companies, allowing them to invest with confidence to advance a given technology beyond the validation stage all the way through to commercialization. During the CTIP evaluation phase, CTIP can help companies navigate the "valley of death" by teaching companies how to assess the ideal strategic fit; matching their device or pivot project to a new device that will have high value to a strategic partner, leading to commercial success.

The group discussed how CTIP can build bridges between the regulatory and reimbursement processes that reside on either side of the valley. For many products, the reimbursement budget is larger than the regulatory budget. The National Science Foundation (NSF) I-Corp program hosted at USC can assist CTIP companies through their entrepreneurship boot camp. Once completed, companies are eligible for NSF development grants. One way CTIP can support the portfolio members is to have a program where we embed a regulatory program graduate student with a portfolio member at a reasonable cost; together, the student and company can create the required documentation. CTIP can also create sample templates for quality management systems, documents/work orders, and templates for regulatory submissions. The Southern California Clinical and Translational Science Institute (USC's Clinical and Translational Science Award) has developed web-based modules for training in clinical and translational science. CTIP could develop a similar set of resources for its portfolio companies.

CTIP and PDCs could provide another type of value to early stage companies: validation. The PDCs might consider developing a joint certification or validation, a "stamp of approval" for early stage innovators, which in some cases can be as valuable as financial support. This can also be of value to more mature companies who need that type of endorsement to pursue investors and customers. It would create some branding and coordination across the PDCs but may be worth pursuing as a value add-on. 
Figure 3. Valley of death: overall process from research to commercialization.

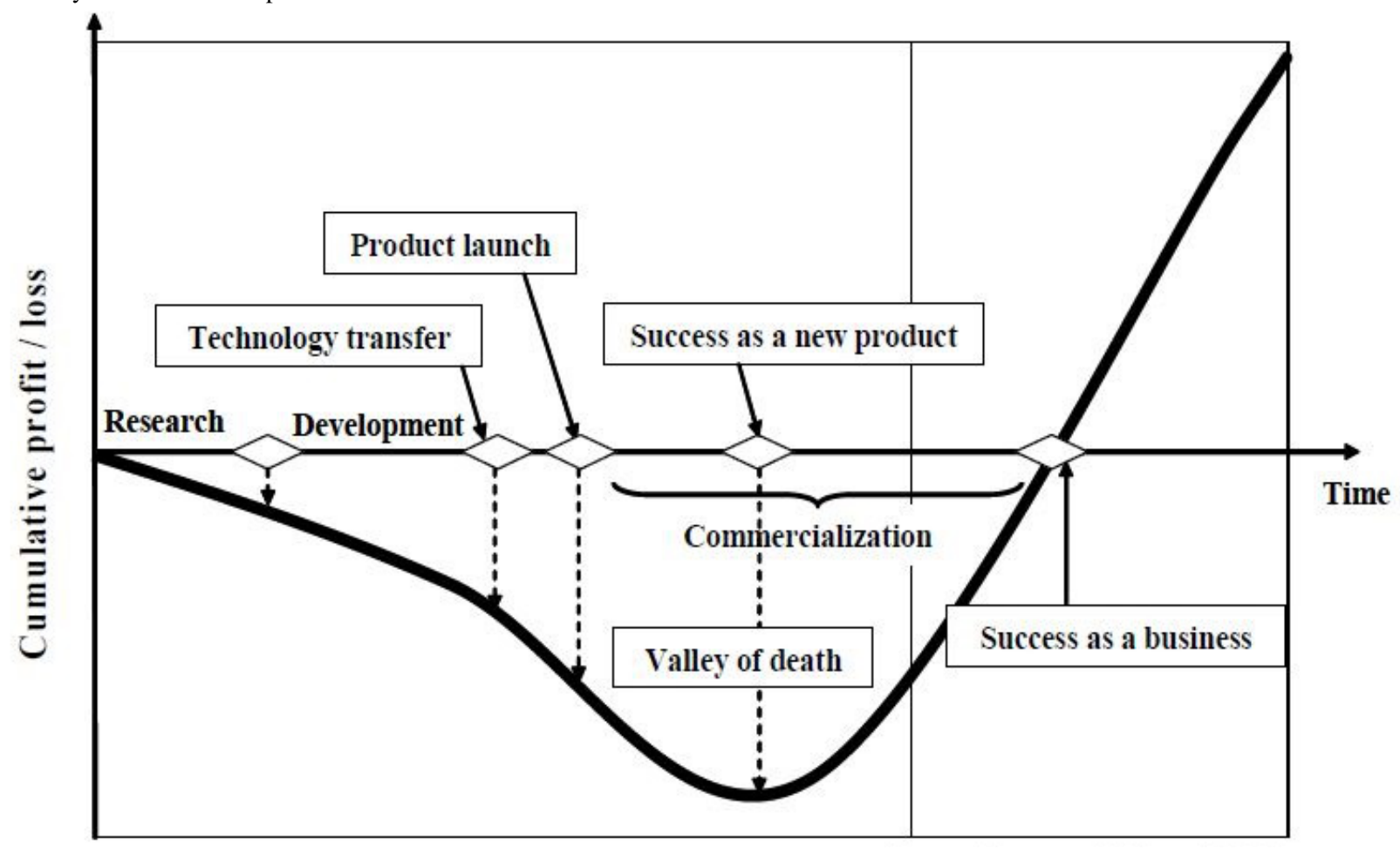

The discussion was extended on the list of templates and checklists that CTIP can create for portfolio members, including the following: (1) tech maturity checklist; (2) quality control checklist; (3) regulatory checklist; (4) reimbursement value analysis; (5) 5-10 elements essential for the company's progression; (6) company self-evaluation; and (7) design control checklist.

CTIP should pursue partnerships with other organizations such as the USC collaborative fund, to sponsor educational events. These events can feature industry experts to discuss a variety of topics, including the development of social capital. Another idea is to host a "shark tank"-style pitch competition with key stakeholders at CHLA and other hospitals. There would be an idea submission process that would include the checklist, and ideas processed are given feedback by the team. There are some retired individuals with regulatory and reimbursement expertise available and are often eager to assist in the process. Many of these experts are looking to find ways to stay involved in the field and give back to the Medtech community. CTIP could play a role in developing a list of individuals who want to provide pro bono services to pediatric medical device innovators.

\section{Conclusions}

As FDA-funded pediatric medical device accelerators, the PDCs are uniquely positioned to not only support pediatric medical device innovators but also raise awareness about the barriers to pediatric medical device development and advocate for both patients and innovators to streamline and accelerate the pathway to the market. Follow-up discussions with Summit attendees also raised challenges that CTIP hopes to address in year 2 . These include the dynamic nature of software regulatory requirements, considerations regarding artificial intelligence and machine learning, and the limitations of other resources based on different devices with different levels of complexity. The ability of artificial intelligence to transform health care by analyzing vast amounts of clinical data presents unique challenges. This includes unstructured datasets, data ownership, and privacy issues to store global data while adhering to evolving regulatory definitions and requirements. These challenges demand engagement from our experienced partners and network to provide novel insights and increase product innovation. Our goal in sharing the proceedings of our annual stakeholder meeting is to provide insights into our process and priorities for individuals, institutions, and agencies with a vested interest in pediatric medical device development who wish to engage in similar work. By sharing these insights, we hope to begin to align efforts and incentives across sectors to achieve our common goal of improving child health outcomes through technology.

\section{Acknowledgments}

The authors would like to express their gratitude to all the participants of the 2019 summit. They would especially like to thank Nandinee Rajyagor for taking notes, Steven Du for helping with the event, Omkar Kulkarni and the Innovation Studio team for their ongoing support and camaraderie, and the staff at the FDA Office of Orphan Products Development for their leadership and support of the PDC program. 
This work was supported by the FDA under award number P50FD006425 (PI: Espinoza) for The West Coast Consortium for Technology \& Innovation in Pediatrics. The funding source had no involvement in the development of this manuscript or in the decision to submit the paper for publication. The content is solely the responsibility of the authors and does not necessarily represent the official views of the FDA.

\title{
Conflicts of Interest
}

None declared.

\section{References}

1. Safe Medical Devices for Children. Washington, DC: The National Academies Press; 2006.

2. Gottlieb S. Public Meeting - Pediatric Medical Device Development. US Food and Drug Administration. 2018. URL: https:/ /www.fda.gov/medical-devices/workshops-conferences-medical-devices/ public-meeting-pediatric-medical-device-development-august-13-14-2018-fda-white-oak-campus-08132018 [accessed 2020-06-01]

3. 2018 FDA/NCATS Report on Unmet Medical Device Needs for Patients with Rare Diseases. US Food and Drug Administration. 2019. URL: http://www.fda.gov/industry/designating-humanitarian-use-device-hud/ 2018-fdancats-report-unmet-medical-device-needs-patients-rare-diseases [accessed 2020-05-26]

4. Bergsland J, Elle OJ, Fosse E. Barriers to medical device innovation. Med Devices (Auckl) 2014;7:205-209 [FREE Full text] [doi: 10.2147/MDER.S43369] [Medline: 24966699]

5. Pediatric Device Consortia Grants Program. US Food and Drug Administration. 2019. URL: http://www.fda.gov/industry/ developing-products-rare-diseases-conditions/pediatric-device-consortia-grants-program [accessed 2020-05-26]

6. Ulrich LC, Joseph FD, Lewis DY, Koenig RL. FDA's pediatric device consortia: national program fosters pediatric medical device development. Pediatrics 2013 May;131(5):981-985. [doi: 10.1542/peds.2012-1534] [Medline: 23569100]

7. FDA Awards Five Grants to Advance the Development of Pediatric Medical Devices. US Food and Drug Administration. 2019. URL: http://www.fda.gov/news-events/press-announcements/ fda-awards-five-grants-advance-development-pediatric-medical-devices [accessed 2020-05-26]

8. National Evaluation System for health Technology (NEST). US Food and Drug Administration. 2019. URL: http://www. fda.gov/about-fda/cdrh-reports/national-evaluation-system-health-technology-nest [accessed 2020-05-26]

9. Real-World Evidence. US Food and Drug Administration. 2019. URL: http://www.fda.gov/science-research/ science-and-research-special-topics/real-world-evidence [accessed 2020-05-26]

10. Michael R, Mumtaz A. The Three Rules: How Exceptional Companies Think. London, UK: The Penguine Group; 2013.

11. Osawa Y, Miyazaki K. An empirical analysis of the valley of death: large - scale R\&D project performance in a Japanese diversified company. Asian J Technol Innov 2006 Jan;14(2):93-116. [doi: 10.1080/19761597.2006.9668620]

\author{
Abbreviations \\ CHLA: Children's Hospital Los Angeles \\ CTIP: The West Coast Consortium for Technology \& Innovation in Pediatrics \\ FDA: Food and Drug Administration \\ IP: intellectual property \\ NSF: National Science Foundation \\ PDC: Pediatric Device Consortia \\ PI: principal investigator \\ R\&D: research and development \\ ROI: return on investment \\ SBIR: small business innovation research \\ STTR: small business technology transfer \\ USC: University of Southern California
}


Edited by $G$ Eysenbach; submitted 17.12.19; peer-reviewed by F Meza, $K$ Chong; comments to author 10.02.20; revised version received 03.04.20; accepted 14.05.20; published 03.07.20

Please cite as:

Espinoza J, Cooper K, Afari N, Shah P, Batchu S, Bar-Cohen Y

Innovation in Pediatric Medical Devices: Proceedings From The West Coast Consortium for Technology \& Innovation in Pediatrics

2019 Annual Stakeholder Summit

JMIR Biomed Eng 2020;5(1):e17467

URL: http://biomedeng.jmir.org/2020/1/e17467/

doi: $10.2196 / 17467$

PMID:

(CJuan Espinoza, Kathryne Cooper, Nadine Afari, Payal Shah, Sriharinarayana Batchu, Yaniv Bar-Cohen. Originally published in JMIR Biomedical Engineering (http://biomedeng.jmir.org), 03.07.2020. This is an open-access article distributed under the terms of the Creative Commons Attribution License (https://creativecommons.org/licenses/by/4.0/), which permits unrestricted use, distribution, and reproduction in any medium, provided the original work, first published in JMIR Biomedical Engineering, is properly cited. The complete bibliographic information, a link to the original publication on http://biomedeng.jmir.org/, as well as this copyright and license information must be included. 